https://dx.doi.org/10.4314/iijikm.v10i1.10

Information Impact:

Journal of Information and Knowledge Management

Vol. 10 (1), June, 2019

ISSN: 2141-4297 (Print) ISSN: 2360-994X (Online)

\title{
Challenges in the Implementation of the Freedom of Information Act in Nigeria
}

\begin{abstract}
Stella Ejitagha
Delta State Polytechnic Library Otefe Oghara

Abstract

This study examined the Challenges in the Implementation of Freedom of Information Act in Nigeria. The research therefore focused on two States in the South-South Region of Nigeria to examine the issues and evaluate the implementation of Freedom of Information Act of 2011. The research objectives include: to ascertain the awareness level of public agencies and institutions on the implementation of FoIA; to determine the constraints in accessing information in agencies and institutions of government resulting in poor implementation; to find out the extent agencies and institutions of government sustain the old order of secrecy in the management of information; and to find out alternative ways the provisions of the Act could be better implemented for easy access to information. The research work adopted the survey method to deeply explicate the issues and questionnaire was used as the research instrument with sample size of 362 out of 6,094 of the population generated from the Australian Calculator. The study found out that a good number of respondents were aware of FoIA but have not or their institutions have not complied with the required implementation of the Act; and that secrecy, bureaucracy, poor record keeping, inadequate knowledge of the provisions of the Act, corruption, and lack of enforcement are some of the inhibiting factors to the implementation of FoIA. It was also found that there is poor public attitude towards openness, transparency and accountability due to narrow mindsets in doing government business under confidentiality. Based on the findings, the study recommended mass enlightenment for public knowledge and understanding of FoIA beyond mere awareness, good record keeping and adoption of modern information management system.
\end{abstract}

\section{Key words: Freedom of Information, FOIA, Nigeria, Secrecy, Mass enlightenment}

\section{Introduction}

Information constitutes the stimulus of all the thoughts, expressions and actions of every living creature. In its various forms, information sets the condition for the functioning of modern society as the measure of success in every area of industry is attributed to the intelligent use of information of the appropriate types. Information is clearly a commodity that can be generated and manipulated to produce more information and high quality information resource becomes fundamental in the drive for decision making. Hence, countries are implementing strategies and policies that enable them take advantage of

Information Impact: Journal of Information and Knowledge Management 10 (1), 2019 Page 123 
the opportunities that are offered by the use of information. Among the strategies are: creating information and communication infrastructure that enables information to flow efficiently and cheaply among their citizens and organizations; developing education and training so that there is a ready supply of appropriately skilled people; supporting the development of the ICT and information content products and services sector to meet the growing demand for information. Efficient flow, access to, and the use of information have become crucial factors in determining the economic strength of nations. Kuunifaa (2011) states that access to information and transparency of governance is essential to ensuring accountability and prevents corruption. Access to information and participation in a democratic society are also mutually dependent.

The provision of information is a key element in citizenship. Citizens need information on the activities of the government to help them contribute meaningfully to the debate on appropriate strategies for socio-economic planning, growth and development. It is apparent that people cannot play their full part in society without access to information. They cannot exercise their rights and claim their entitlements without information, nor can they participate fully in democratic processes.
Therefore, access to information, in the spirit and letters of the Freedom of Information (FoI), implies a citizen's right to access information that is held by the state. It is the ability of citizens of a country to have free access to information enabled by legislation. In many countries, this freedom is supported as a constitutional right. Freedom of information obliges government to disclose as much as is possible about its workings. The argument behind this is that if a democracy is to function effectively, its citizens must be fully informed as to how it operates. Freedom of information legislation is not new - Sweden enacted the law as early as 1766 and Finland in 1919. In the past decades, a record number of countries from around the world have also taken steps to enact the legislation giving effect to access right. In doing so, Nigeria has joined those countries that had enacted such laws some time ago, such as Sweden, United States, Finland, the Netherlands, Australia and Canada. The spread of laws providing rights to access information reflects the prevailing belief that access to information is one essential pillar in a strategy to improve governance, reduce corruption, strengthen democracy through enhanced participation and increase development (Darch \& Underwood, 2010). 
Ejitagha, S: Challenges in the Implementation of the Freedom of Information Act in Nigeria

Unfortunately, the utmost confidentiality tied to official secrecy has become the norm in all facets of government operations in Nigeria even after the enactment of the Act in 2011, thus frustrating the clear implementation of the

\section{Objectives of the Study}

The goal of this study is to identify the challenges that have hindered the proper implementation of the Freedom of Information Act which is meant to promote transparency, accountability and good governance as a pivot for the growth of a democratic society like Nigeria. Specifically, it is to:

\section{Methodology}

The survey research method was adopted for this study. The population of this study was drawn from employees of some selected Federal Agencies and Institutions from two states of the South-South geopolitical zone of Nigeria, namely
Act for the good of society. There are still constraints frustrating the access to information in government agencies and institutions due to poor or almost absence of implementation of the FoIA. This is the crux of this study.

1). ascertain the awareness level of public agencies and institutions on the implementation of FoIA

2). examine the constraints in accessing information in agencies and institutions of government as a result of poor implementation of the FoIA.

4). find out alternative ways the provisions of FoIA can be better implemented and make information more accessible.

Rivers and Delta States. The Federal agencies and institutions are considered most appropriate as FoIA is an Act of the Federal Government of Nigeria and therefore relate more to its organs and agencies.

Table 1: Distribution of Employees of Federal Public Institutions in Delta \& Rivers States.

\begin{tabular}{|l|l|l|}
\hline S/N & State & $\begin{array}{l}\text { Federal employees in federal } \\
\text { agencies/institutions in the } \\
\text { State }\end{array}$ \\
\hline 01 & Rivers & 1,675 \\
\hline 02 & Delta & 4,419 \\
\hline \multicolumn{2}{|l|}{ Total } & $\mathbf{6 , 0 9 4}$ \\
\hline
\end{tabular}

In view of the near impossibility of of the Universe of the study within the studying or sampling the entire population limited time frame, the researcher drew a 
Ejitagha, S: Challenges in the Implementation of the Freedom of Information Act in Nigeria

representative sample using the National

Statistical Service Size Calculator of

Australia

(http://www.nss.gov.au/nss/home.nsf/pages

Sample+size+calculator) which

determined the confidence interval, standard error as well as relative standard error with confidence level of $95 \%$. When the population size of 6,094 and confidence interval of 0.05 were entered into the calculator, the result shows a sample size of 362 .

The study used questionnaire as instrument for data collection. The data collected where analysed using the descriptive statistics of frequency count and simple percentage to make for easy interpretation and comprehension.

\section{Result and Findings}

\section{Presentation of Data}

\section{Demographic variables}

Table 2. Gender Distribution of Respondents

\begin{tabular}{|l|l|l|}
\hline Variable & Frequency & Percentage \\
\hline Male & 228 & 63 \\
\hline Female & 134 & 37 \\
\hline Total & 362 & 100 \\
\hline
\end{tabular}

Table 2 above shows that of the 362 respondents, 228, that is, 63 percent were male while 134 representing $37 \%$ were females. Even though, the distribution of Table 5: Distribution of Educational Qualification of Respondents

\begin{tabular}{|l|l|l|}
\hline Variable & Frequency & Percentage \\
\hline WAEC/NECO/SSCE & 4 & 1 \\
\hline OND/NCE/HND & 48 & 13 \\
\hline BA/B.Sc & 230 & 64 \\
\hline MA/M.Sc/PhD & 80 & 22 \\
\hline Total & 362 & 100 \\
\hline
\end{tabular}

Table 2 represent the distribution of educational qualification of respondents as it would be relevant in determining their the instrument was not deliberately tailored towards a particular gender, the female had a fair share in the sample. 
Ejitagha, S: Challenges in the Implementation of the Freedom of Information Act in Nigeria

64 percent possesses Bachelors degrees, 80 or Higher National Diploma while 4 of the respondents, that is, $22 \%$ had higher respondents $(1 \%)$ had Senior School degrees, 13\%(48) had either Ordinary Certificate.

Diploma, National Certificate of Education

\section{Awareness level of public agencies and institutions on the implementation of FoIA}

Table 3: Are you aware of the Freedom of Information Act in Nigeria?

\begin{tabular}{|l|l|l|}
\hline Variable & Frequency & Percentage \\
\hline Yes & 290 & 80 \\
\hline No & 72 & 20 \\
\hline Total & 362 & 100 \\
\hline
\end{tabular}

This item seeks to know if the The result shows that 290 , representing 80 respondents are aware of the enactment of percent are very much aware while $20 \%$ the Freedom of Information Act in Nigeria. (72) are not aware.

Table 4: Whether they have access to copy(ies) of the FoIA in their offices and if they have read the relevant sections.

\begin{tabular}{|l|l|l|}
\hline Variable & Frequency & Percentage \\
\hline Yes & 150 & 41 \\
\hline No & 212 & 59 \\
\hline Total & 362 & 100 \\
\hline
\end{tabular}

This item seeks to determine the knowledge of the respondents who initially claimed to have awareness of the enactment of the FoI Act in Nigeria. Unfortunately, 212 out of the 362 respondents, that is, 59 percent claimed that they have no access to copy(ies) of the
Act in their offices and so have not read the relevant sections of the Act to gain knowledge of the relevant sections while $150(41 \%)$ claimed to have access to the copies of the act in their offices and have read the sections. 


\section{Constraints frustrating access to information in agencies and institutions of government} resulting from implementation

Table 5a, b, c: a). Ignorance of the servants comply to provide information; c). provisions of the act encourages poor implementation and make public servant apply official secret act; b). It is by Inaccessibility to information in public institution is attributable to poor culture of compulsion of the courts that public record keeping.

\begin{tabular}{|c|c|c|c|c|c|c|}
\hline \multirow[t]{2}{*}{ Variable } & \multicolumn{2}{|c|}{$\begin{array}{l}\text { 5a). Ignorance of the } \\
\text { provisions of the act } \\
\text { encourages poor } \\
\text { implementation and } \\
\text { make public servant } \\
\text { dwell in confidentiality } \\
\text { based on official secret } \\
\text { act }\end{array}$} & \multicolumn{2}{|c|}{$\begin{array}{l}\text { 5b). It is by compulsion } \\
\text { of the courts that public } \\
\text { servants comply to } \\
\text { provide information } \\
\text { otherwise request for } \\
\text { information will be } \\
\text { denied }\end{array}$} & \multicolumn{2}{|c|}{$\begin{array}{l}5 \mathrm{c}) \text {. Inaccessibility to } \\
\text { information in public } \\
\text { institution is attributable } \\
\text { to poor culture of record } \\
\text { keeping and retrieval } \\
\text { process }\end{array}$} \\
\hline & No & $\%$ & No & $\%$ & No & $\%$ \\
\hline $\begin{array}{l}\text { Strongly } \\
\text { Agree }\end{array}$ & 138 & 38 & 93 & 26 & 127 & 35 \\
\hline Agree & 170 & 47 & 180 & 50 & 154 & 43 \\
\hline Undecided & 16 & 4 & 28 & 8 & 18 & 5 \\
\hline Disagree & 32 & 9 & 47 & 13 & 40 & 11 \\
\hline $\begin{array}{l}\text { Strongly } \\
\text { Disagree }\end{array}$ & 6 & 2 & 14 & 3 & 23 & 6 \\
\hline Total & 362 & 100 & 362 & 100 & 362 & 100 \\
\hline$\frac{\mathrm{AR} \times \mathrm{W}}{4.00}$ & & & & $1377=4.00$ & & $\underline{1408}=$ \\
\hline $\mathrm{R} \times \mathrm{NQ}$ & & & & 362 & & 362 \\
\hline
\end{tabular}

The items in table $5 \mathrm{a}, \mathrm{b}, \mathrm{c}$ seek to prove that ignorance of the provisions of the act encourages the public servants to dwell in confidentiality and promote

official secrecy; and to that effect, government employees can only comply to 
disclose information through compulsion by the courts; and that poor culture of record keeping frustrates access to information.

Therefore, in table 5a, a cumulative of 308 respondents, representing 85 percent agree (138 strongly agree and 170 agree) that ignorance of the provisions of the act in a way encourages poor implementation, resulting in public servants in government agencies and institutions to dwell in confidentiality based on official secret and other inhibiting acts such as oath of secrecy in office. Whereas, only $11 \%$ representing 38 respondents disagreed and $16(4 \%)$ were undecided. The position of the 308 respondents who agree to the position was significant as the computed figure based on 5-Likert scale was 4.11.

Table $5 \mathrm{~b}$ indicates that of the 362 respondents, 273 , that is, 76 percent were of the view that it is only by compulsion of the courts that public servants can comply to provide information otherwise, request for information will be denied or not honoured at all. Also, 61 respondents, representing $16 \%$ disagree, while $28(8 \%)$ were undecided. Significantly, the position of the 273 respondents reflected in the computed figure of 4.00 based on 5-Likert scale. Table $5 \mathrm{c}$ shows that cumulative of 281 (127 strongly agree and 154 agree) respondents representing 78 percent agreed that inaccessibility to information in public institutions is attributable to poor culture of record keeping and retrieval process, whereas $17 \%$ (63) of the respondents disagree and $18(5 \%)$ respondents were undecided. The position of the 281 respondents who agree was also significant in the computed figure based on 5-Likert scale of 4.00 .

\section{Ways FoIA can be better implemented to make information in Nigeria more accessible and ameliorate the challenges}

Tables 6a, b, c: a) Mass enlightenment and public knowledge of the provisions of FoIA to enhance implementation; b). Making government activities open and transparent to enhance implementation; c).
Repealing conflicting laws that hinder compliance and appointment of National Commissioner of Ombudsman for effective implementation 


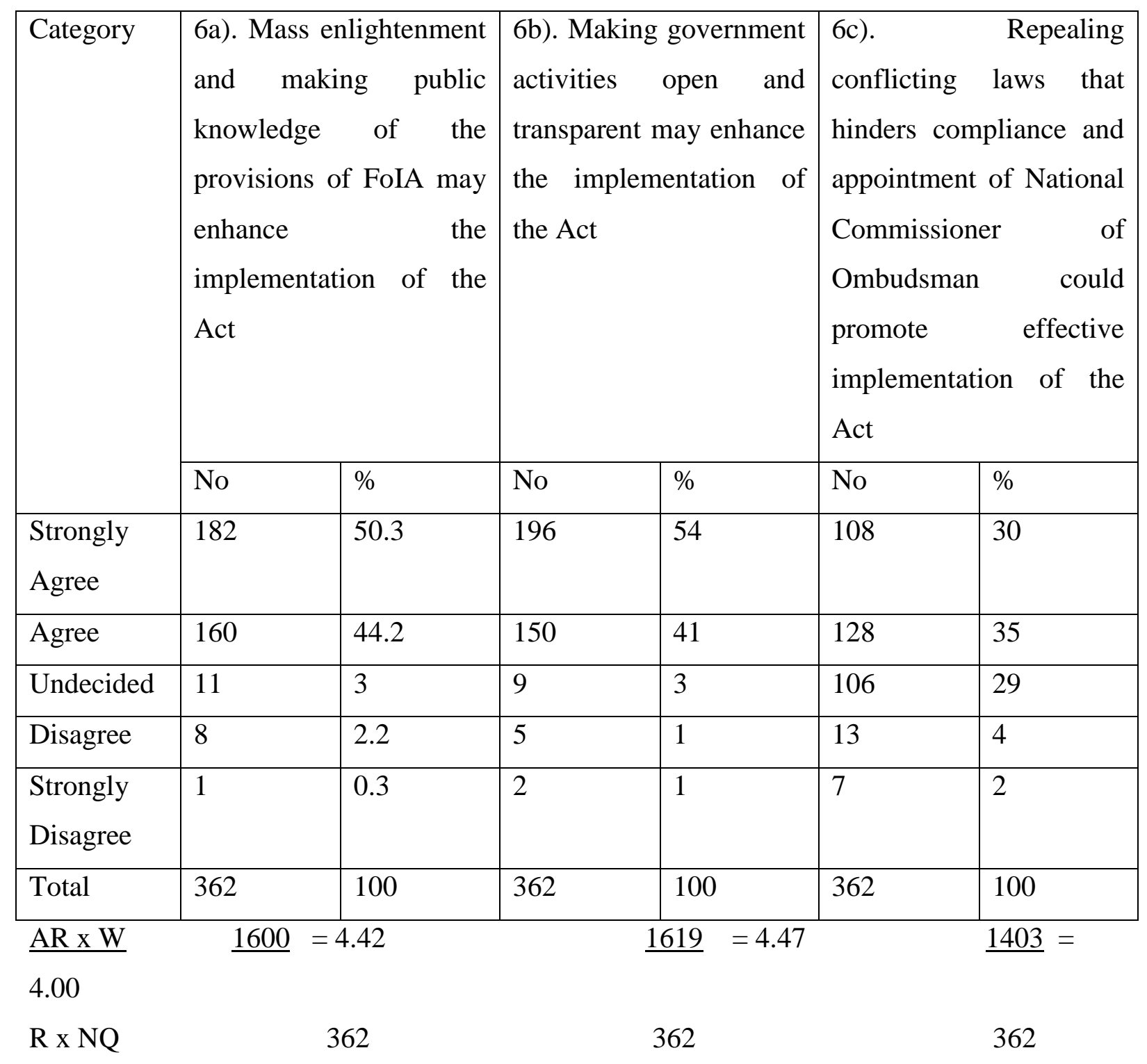

Considering the items in table $6 \mathrm{a}, \mathrm{b}, \mathrm{c}$ the study wanted to know if mass enlightenment and making public knowledge of the provisions of FoIA enhances the implementation of the Act; also if making government activities open and transparent enhances implementation of the Act; and if repealing conflicting laws that hinders compliance and appointment of National Commissioner of
Ombudsman promotes effective implementation of the act.

Thus, table 6 a above shows that out of the 362 respondents, 350 (182 strongly agree and 160 agree) representing 94.5\% overwhelmingly agree that mass enlightenment to create public knowledge of the Act would certainly enhance the implementation of the Act, while a paltry number of $9(2.5 \%)$ of the respondents disagree and $11(3 \%)$ were undecided on 
Ejitagha, S: Challenges in the Implementation of the Freedom of Information Act in Nigeria

the matter. The agreement on mass enlightenment to create public was very

Again, on the issue of making government activities open and transparent to enhance the implementation, table $6 \mathrm{~b}$ indicates that 354 of the respondents, that is, $95 \%$ supported the idea while $7(2 \%)$ disagree with $9(3 \%)$ undecided on the issue. By the overwhelming support from 354 respondents, it was quite significant that open and transparent governance would enhance implementation of the Act as shown in the computed figure of 5Likert scale which was 4.47 .

In addition, table $6 \mathrm{c}$ reveals that 236 respondents or 65 percent of the

\section{Discussion of Findings}

The findings showed that out of 362 questionnaire analysed 290, representing 80 percent said they are very much aware of the enactment and existence of the Freedom of Information Act in Nigeria. In contrast, 212 out of the 362 respondents, that is, $59 \%$ however said that they have no access to copy(ies) of the Act in their offices and so have not read the relevant sections of the Act to gain knowledge of the provisions, whereas $150(41 \%)$ claimed to have access to the copies of the Act in their offices and have read the sections. This means that merely being aware is not having the knowledge of the provisions of significant with the computed figure of 5Likert scale at 4.42

respondents agreed that repealing conflicting laws that hinders compliance and appointment of National Commissioner of Ombudsman would certainly promote effective implementation of the Act. However, 20 respondents representing 6\% disagreed while 106(29\%) were undecided. The support for the repeal and appointing a Commissioner for Ombudsman was significant by the computed figure of 5-Likert scale which was 4.00 .

the Act to take the actions required even as public servants.

It was further observed that ignorance of the provisions of the Act in a way encourages poor implementation and this results in public servants dwelling in confidentiality based on official secret and other inhibiting acts to deny the public access to information which was corroborated by the views of 308 respondents, representing $85 \%$ analysed. While probing further, the study also revealed that public servants are relying more on the official confidentiality as reasons not to comply with request for information even if it is for public interest 
and this was expressed by a significant majority of the respondents, 303(84\%). In the views of Afolayan (2012, p.10) what affects Freedom of Information Act is "the act in some laws that are fully operational in Nigeria...for instance, there is the Official Secrets Act, Evidence Act, the Public Complaints Commission Act, the Statistic Act and the Criminal Code; all aimed at suppressing the free flow of information. All these laws may affect the effectiveness of the Act in the long run as some mischievous public officers can use these aspects of the Acts for their selfish purposes." "Indeed, the veil of secrecy makes it difficult to get information from any government agency" (Ayode, 2011). Again, Afolayan (2012) notes that "plethora of laws prevent civil servants from divulging official facts and figures, notably the official Secrets Acts which makes it an offence not only for civil servants to give out government information but also for anyone to receive or reproduce such information."

Also Adeleke (2011) maintains that the idea behind these laws is to protect vital government information, but the level of secrecy is too ridiculous that some classified government files contain ordinary information like newspaper cuttings which are already in the public domain, so impenetrable is the veil of secrecy that government departments withhold information from each other under the guise of official secrets legislation. On the compulsion of public servants or government agencies by the courts to comply with providing information to the public, otherwise such request will be denied, $273(76 \%)$ of the respondents strongly supported the opinion. The study also found that a significant $281(78 \%)$ respondents agree that inaccessibility to information in public institution is attributable to poor culture of record keeping and retrieval process.

The research revealed that the implication of whether the exemption clauses in the Act are exerting enormous constraints on the implementation of the Act, however showed the height of ignorance of the respondents with $208(58 \%)$ claiming that they cannot exactly say if the clauses are serving as constraints, which could lead to further research on measuring awareness, Knowledge, adoption and implication. This is because in the same manner 194(54\%) of the respondents could not ascertain if the proviso of "denial shall not apply where public interest takes precedence" enhance public access to information. This, incidentally correlates with the earlier views on exemption clauses.

This finding tends to corroborate the views of Ogbuokiri (2011) which says the Freedom of Information Act in Nigeria 
contains more exemption sections and clauses than sections that grant access to information, adding that some mischievous public officers can use the sections for unjust and mischievous purpose. According to him, only sections 1 and 3 grant access to information while as many as ten sections which include sections 7, $11,12,14,15,17,18,19$ and 26 are meant to deny the public access to information.

\section{Conclusion and Recommendations}

The FoI Act has been described by several authors as the right that enables members of the public to have access to information held by government bodies, and even private organizations. Following this fact, freedom of information is a fundamental human right which Nigerians are entitled to. The public is entitled to the truth, and only correct information can form the basis for sound entrenchment of democracy and assurance of confidence of the public in their government. However, the Act would amount to a waste of efforts if the public who should use it are ignorant of its provisions and if its implementation is further frustrated by such factors as revealed by the findings of this study. It is only when the law is in use that it can get people informed, reduce corruption, ensure transparency and improve governance in the country.
Further findings from the study indicated that improved record keeping and adopting modern information system could enhance the implementation of the act with $318(88 \%)$ in support. And it was also revealed from the analyses of the data which showed an overwhelming support for mass enlightenment to create public knowledge of the Act in order to enhance the implementation of the Act as expressed by $350(94.5 \%)$ of the respondents.

In spite of the above challenges as revealed by the findings of this study, it is also necessary to proffer some tenable solutions based on suggestions provided by research. It is based on the above assertion that the study proffer the following recommendations to entrench an effective and workable Freedom of Information Act in Nigeria.

(a) Mass enlightenment for public understanding of FoIA. There is the urgent need to adopt multimedia approach to publicise the FoIA, not only in the urban areas, but also in the rural communities, to enlighten the public on the need for, and the benefits of the act as well as their rights and responsibilities. Other methods of disseminating information easily to people should be devised; such as making certain types of information accessible at some outlets as public libraries, newspaper 
Ejitagha, S: Challenges in the Implementation of the Freedom of Information Act in Nigeria

vendors' stands, town halls, churches and mosques.

\section{References}

Adeleke, F. (2011). Prospect and challenges of FOI bill in Nigeria. Retrieved fromtp://www.elombah.com/index.php/arti cles-mainmemu

Afolayan A. (2012) A critical Analysis of Freedom of Information Act in Nigeria. Retrieved from www.odinakadotnet.wordpress.com/2012/ 08.

Ayode, S. (2011) Right Nigeria: Freedom of Information Bill Elusive. Retrieved from http://www.info.rights.com.

FOIA (2011). Freedom of Information Act (2011). Retrieved from http://www.nassnig.org/nass2/acts.php

Darch, C. \& Underwood, P. G. (2010). Freedom of information in the developing world: the citizen, the state and models of openness. Oxford, Cambridge, New Delhi: Chandos Publishing.

Kuunifaa, C. D. (2011). Access-toinformation legislation as a means to achieve transparency in Ghanaian governance: lessons from the Jamaican experience. Paper presented at World Library and
Information Congress, 77th IFLA General Conference and Assembly, 13-18 August, 2011, Puerto Rico. Retrieved

frttp://conference.ifla.org/ifla77 